\title{
Daily intake of dairy products in Brazil and contributions to nutrient intakes: a cross-sectional study
}

\author{
Mary M Murphy ${ }^{1, *}$, Leila M Barraj ${ }^{1}$, Lindsey D Toth ${ }^{2}$, Laura S Harkness ${ }^{2}$ and Douglas R Bolster ${ }^{2}$ \\ 'Exponent, Inc., Center for Chemical Regulation \& Food Safety, 1150 Connecticut Avenue, NW, Washington, DC \\ 20036, USA: ${ }^{2}$ PepsiCo Global R\&D Nutrition, Chicago, IL, USA
}

Submitted 6 October 2014: Final revision received 31 March 2015: Accepted 24 April 2015: First published online 19 June 2015

\begin{abstract}
Objective: Dairy products are sources of protein and micronutrients important in a healthy diet. The purpose of the present analysis was to estimate consumption of dairy products by Brazilians and identify contributions of dairy products to nutrient intakes.

Design: Dairy consumption data were obtained from 24 h dietary records. Dairy products were defined as milk (including flavoured), cheese and yoghurt. Estimates of dairy product intakes were generated for all individuals, individuals in urban and rural households and for age groups 10-18 years, 19-59 years and $\geq 60$ years. Contributions to nutrient intakes were estimated for the total sample and sub-populations.

Setting: Nationwide cross-sectional survey, 2008-2009.

Subjects: Nationally representative sample of individuals aged $\geq 10$ years in the Individual Food Intake survey, a component of the Brazilian Household Budget Survey ( $n$ 34 003).

Results: Among individuals aged $\geq 10$ years, per capita intake of dairy products was 142 (SE 2.1) g/d. Dairy product intake was higher among individuals in urban compared with rural areas and among groups $10-18$ years and $\geq 60$ years compared with adults aged $19-59$ years. Dairy products accounted for $6 \cdot 1 \%$ of daily energy intake, $7 \cdot 3 \%$ of protein, $16.9 \%$ of saturated fat, $11.1 \%$ and $4.3 \%$ of total and added sugars, respectively, and $10 \cdot 2-37.9 \%$ of daily Ca, vitamin D, P, vitamin A and $\mathrm{K}$. Conclusions: Dairy products were substantial contributors to daily intakes of selected nutrients of concern in Brazil, although mean daily dairy product consumption was less than a typical portion. Education efforts in Brazil to raise awareness about the nutritional role of dairy foods may serve to improve overall diet quality.
\end{abstract}

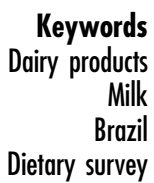

Dairy products including milk and milk-derived foods are naturally rich sources of protein and micronutrients important for health, including $\mathrm{Ca}, \mathrm{Mg}, \mathrm{P}, \mathrm{K}$ and vitamins $\mathrm{A}$ and $\mathrm{B}_{12}{ }^{(1)}$. Several of the micronutrients concentrated in milk and dairy products have been identified as nutrients of concern in Brazil based on analyses of the first nationwide dietary survey conducted in 2008-2009 by the Brazilian Institute of Geography and Statistics (Instituto Brasileiro de Geografia e Estatística, IBGE). This recent survey revealed a high percentage of the population or sub-populations with intakes of $\mathrm{Ca}$, vitamin $\mathrm{A}, \mathrm{P}$ and $\mathrm{Mg}$ below recommended levels; dietary intakes of $\mathrm{K}$ and vitamin $\mathrm{D}$ were also suboptimal ${ }^{(2-5)}$.

Low intake of dairy products has been associated with higher dietary inadequacy of some micronutrients including $\mathrm{Ca}, \mathrm{Mg}$ and $\mathrm{K}^{(6-8)}$. In both Brazil and the USA, low consumption of milk and milk products has been identified as a factor in suboptimal diet quality ${ }^{(9,10)}$.

The current Brazilian dietary guidelines, released in 2014, provide qualitative recommendations for making food choices that promote health and well-being ${ }^{(11)}$. The guidelines advise consumption of fresh and minimally processed foods as the basis of the diet with limited consumption of processed and ultra-processed foods. Dairy products including fluid and powdered milk and yoghurt without added sugar are examples of minimally processed foods encouraged for consumption, while cheese and sweetened and flavoured yoghurts and dairy drinks are among the processed or ultra-processed foods for which limited consumption is recommended.

The 2014 Brazilian dietary guidelines do not provide quantitative recommendations for intake of specific foods. 
However, the previous edition of the Brazilian dietary guidelines, released in 2006, was based in part on dietary guidelines from the USA and recommended intake of three portions of milk and dairy products per day to help meet nutrient needs, with additional guidance for adults to choose low-fat milk and dairy products ${ }^{(12,13)}$.

To our knowledge there is not an analysis of total milk and dairy product intake in Brazil or information on the nutritional contributions of dairy products in the diet using the first nationwide dietary survey in Brazil. Such an analysis would provide important information on dairy consumption in Brazil, which in turn could help guide nutrition education efforts to support quantitative and qualitative shifts in intake of dairy foods. The purpose of the present data analysis was to estimate consumption of dairy products of specific subpopulations in Brazil and to identify the contributions of dairy products to overall nutrient intakes using recent nationally representative food consumption data.

\section{Methods}

\section{Sample}

The study population for the current assessment was a sample of individuals aged $\geq 10$ years who participated in the first nationwide dietary survey in Brazil. The dietary survey, or Individual Food Intake component, was conducted by the IBGE and completed as part of the Brazilian Household Budget Survey in 2008-2009. A probabilistic sample of 55970 permanent private households participated in the Household Budget Survey from May 2008 to May 2009; a randomly selected sub-sample of 13569 households from the Household Budget Survey participated in the Individual Food Intake component. A total of 34003 individuals provided individual food intake data via dietary records. The survey was conducted in accordance with Federal Law number 5534 (14 November 1968) which guarantees confidentiality of the gathered information.

\section{Dietary intake data}

Each individual participating in the dietary survey component completed $24 \mathrm{~h}$ dietary records of all foods consumed on two non-consecutive days. Respondents were instructed to maintain a record of each food consumed, along with the method of preparation, the amount of food consumed in common measures, and the time and place of intake (at home or away). The respondents were provided manuals with detailed instructions, including pictures of household measures, to guide in the estimation of food portions in the records. Additionally, respondents completed a separate questionnaire on typical use of sugar or sugar substitutes (sugar, artificial sweetener, both or none). Following completion of the dietary records, survey participants subsequently attended an interview in which trained survey staff reviewed the dietary records and inquired about any additional foods and beverages that may have been consumed. The record review included probes of intervals of at least $3 \mathrm{~h}$ in which no food or beverage was recorded and days on which fewer than five foods were recorded to confirm the information was correct. The survey data release provides the amount of each food consumed in units as reported and in units of gram weight. Conversions to gram weights were made by IBGE using a database of portion weight measures compiled for foods reported in the survey. The current analysis was based on the first day of food records.

\section{Identification of dairy products and dairy portions}

All foods reported consumed in the dietary survey were categorized by IBGE into one of twenty-one food groups; within each food group, similar food items were categorized into subgroups. IBGE's dairy food group includes fluid and powdered milk (whole, reduced-fat and non-fat forms), milk-based grain preparations (e.g. porridge), cream, cheese, yoghurt, milk drinks (e.g. dairy and fruit smoothies; kefir, fermented milk) and diet or light versions of these foods. For the current analysis all items in the IBGE dairy group other than cream were classified as dairy products. Items from other food groups classified as dairy products in the current analysis include flavoured milk (e.g. chocolate milk), milk consumed with coffee (i.e. 'coffee with milk') and cheese sauce. Based on the nutrient composition data, $50 \%$ of the weight of each reported intake of coffee with milk was assumed to be milk (whole milk, with 3.5-4\% fat). Total milk represented fluid and powdered milk, milk drinks, flavoured milk, milk consumed in coffee and grains cooked in milk. Milk-based desserts were not categorized as dairy products in the current analysis. Total dairy products were defined as total milk, cheese and yoghurt.

With the exception of 'coffee with milk', mixtures were not disaggregated as the survey documentation does not include recipes for disaggregating all mixtures into component ingredients. This classification of dairy products therefore did not capture the dairy component of mixtures containing milk, cheese or yoghurt, such as cheese on pizza, cheeseburgers or sandwiches, or milk in a creamed soup. These foods are not among the most commonly consumed foods in Brazil. Pizza, for example, was reported consumed by just $2 \%$ of the population ${ }^{(14)}$. Contributions of these mixtures to total dairy consumption were therefore presumably small.

Guideline 5 in the 2006 Brazilian dietary guidelines recommends daily intake of three portions of milk and dairy for all individuals ${ }^{(12)}$. The Brazilian dietary guidelines include a reference table of gram weights for portions of dairy products ${ }^{(12)}$; these reference data along with the IBGE database of portion weight measures for 'one portion' were used to identify a gram weight per portion of each type of dairy product reported consumed ${ }^{(5)}$. The gram weight portion size assumed for fluid milk, flavoured 
milk and most milk drinks in the current analysis was $182 \mathrm{~g}$, which is approximately $200 \mathrm{ml}$. The portion size assumed for milk-based smoothies was $171 \mathrm{~g}$ based on the reported reference weight for these beverages. For milkbased grain preparations, $195 \mathrm{~g}$ was counted as one portion. The gram weight portion size used for ricotta cheese was $100 \mathrm{~g}$ and the portion size for other types of cheese ranged from 30 to $50 \mathrm{~g}$, or approximately 1 to $1 \frac{1 / 2}{2}$ slices. The gram weight portion size used for yoghurt was $165 \mathrm{~g}$.

\section{Nutrient composition data}

Dietary intakes of total energy, protein, carbohydrate, total sugars, added sugars, total fat, saturated fat, cholesterol, vitamin $\mathrm{A}$, riboflavin, vitamin $\mathrm{B}_{6}$, vitamin $\mathrm{B}_{12}$, vitamin $\mathrm{D}, \mathrm{Ca}$, $\mathrm{P}, \mathrm{Mg}, \mathrm{Zn}, \mathrm{Na}$ and $\mathrm{K}$ were estimated from total dairy products and also from milk, cheese and yoghurt. Estimates of nutrient intakes were calculated with nutrient data in the food composition data tables compiled explicitly for use with the dietary survey and for estimating nutrient intakes, including prevalence of inadequacy ${ }^{(5)}$. Nutrient values in these food composition tables were compiled by IBGE primarily from the Brazilian Food Composition Table (Tabela Brasileria de Composição de Alimentos Campinas, TACO) and supplemented with values from the Nutrition Data System for Research (NDSR) of the University of Minnesota (vitamins $\mathrm{B}_{12}$ and $\mathrm{D}$, total and added sugars) and additional data sources ${ }^{(14)}$. The food composition tables provide nutrient values per $100 \mathrm{~g}$ edible portion of food by specific method of preparation for most although not all foods. We did not impute values for any unquantified nutrient values in the food composition tables; these values were assumed to be zero in estimates of nutrient intakes.

\section{Statistical analysis}

Using the first day of food records from each respondent, mean daily intake of milk, cheese, yoghurt and all dairy products combined was estimated in units of grams and portions. Estimates of total dietary nutrient intakes included standardized adjustments for fried meats to account for typical addition of oil. Levels of sugar added to commonly sweetened beverages such as coffee, tea and fruit-based drinks were estimated as $10 \%$ of the beverage weight for typical users of sugar and $5 \%$ of the beverage weight for typical users of a combination of sugar and sugar substitutes. Percentage nutrient contributions provided by dairy products were estimated using the population proportion method ${ }^{(15)}$. Estimates were developed for the population aged $\geq 10$ years; sub-populations by location of residence, i.e. urban and rural; and subpopulations by age, i.e. adolescents aged 10-18 years, adults aged $19-59$ years and adults aged $\geq 60$ years.

Estimates were based on one day of food intake, an approach appropriate to estimate mean intakes by a population $^{(16,17)}$. All estimates were calculated with sampling weights and adjusted for the complex sampling design. Statistical analyses of dairy product intakes $(\mathrm{g} / \mathrm{d}$ and portions/d) were carried out in the statistical software package STATA version $12 \cdot 1$. Intakes in different regions were compared using the adjusted Wald test. Mean intakes of dairy products by age group were compared using the adjusted Wald test and pairwise post hoc comparisons. Level of significance was defined as $P<0 \cdot 05$. $P$ values of the pairwise post hoc analyses were adjusted for multiple comparisons using the Sidak method.

\section{Results}

\section{Proportion of the population reporting consumption of dairy products}

Dairy products as defined in this analysis were consumed by the majority of the Brazilians aged $\geq 10$ years (Table 1 ). Milk, including plain milk (as a beverage, in coffee or in cooked cereal), flavoured milk and milk drinks, was the most common type of dairy product consumed, with $56 \%$

Table 1 Percentage of consumers and per capita intake of dairy products in the Brazilian population aged $\geq 10$ years by location of household. Individual Food Intake 2008-2009; first day of intake

\begin{tabular}{|c|c|c|c|c|c|c|c|c|c|c|}
\hline & & & & \multicolumn{6}{|c|}{ Location of household } & \multirow[b]{3}{*}{$P$ value } \\
\hline & \multicolumn{3}{|c|}{ Brazil ( $n 34003)$} & \multicolumn{3}{|c|}{ Urban (n 25 753) } & \multicolumn{3}{|c|}{ Rural ( $n$ 8250) } & \\
\hline & $\%$ & Mean & SE & $\%$ & Mean & SE & $\%$ & Mean & SE & \\
\hline Total dairy ${ }^{*}(\mathrm{~g} / \mathrm{d})$ & 62 & 142 & $2 \cdot 1$ & 64 & 147 & $2 \cdot 4$ & 51 & 114 & $4 \cdot 4$ & $<0.001$ \\
\hline Milk† (g/d) & 56 & 124 & 1.9 & 58 & 127 & $2 \cdot 1$ & 48 & 105 & $4 \cdot 1$ & $<0.001$ \\
\hline Cheese $(\mathrm{g} / \mathrm{d})$ & 14 & 7 & 0.3 & 15 & 8 & 0.3 & 8 & 4 & 0.4 & $<0.001$ \\
\hline Yoghurt $(g / d)$ & 4 & 11 & 0.6 & 5 & 12 & 0.7 & 2 & 5 & 0.6 & $<0.001$ \\
\hline Total dairy ${ }^{*} \neq$ (portions/d) & 62 & 0.9 & 0.01 & 64 & 1.0 & 0.01 & 51 & 0.7 & 0.01 & $<0.001$ \\
\hline Milk†,‡ (portions/d) & 56 & 0.7 & 0.01 & 58 & 0.7 & 0.01 & 48 & 0.6 & 0.01 & $<0.001$ \\
\hline Cheesef (portions/d) & 14 & 0.2 & 0.01 & 15 & 0.2 & 0.01 & 8 & 0.1 & 0.01 & $<0.001$ \\
\hline Yoghurtł (portions/d) & 4 & 0.1 & $<0.005$ & 5 & 0.1 & $<0.005$ & 2 & $<0.05$ & $<0.005$ & $<0.001$ \\
\hline
\end{tabular}

*Total dairy values may not equal sum of milk, cheese and yoghurt values due to rounding.

†Milk includes plain and flavoured milk, milk drinks, grains cooked in milk and milk in coffee.

$\ddagger$ Weight per portion: milk, $182 \mathrm{~g}$; milk-based smoothies, $171 \mathrm{~g}$; grains cooked in milk, $195 \mathrm{~g}$; powdered milk, 26 or $34.5 \mathrm{~g}$; cheese, 30 to $50 \mathrm{~g}, 100 \mathrm{~g}$ for ricotta cheese; yoghurt, $165 \mathrm{~g}$. 
of Brazilians reporting intake of milk on the day of recall. Milk in coffee was the most common form of milk intake for most individuals. Coffee with milk was reported consumed by $36 \%$ of the total population in contrast to $14 \%$ of the population consuming fluid plain milk, $10 \%$ consuming flavoured milk or a milk drink, and $2 \%$ consuming grains cooked in milk (data not shown). Fluid milk (excluding milk in coffee with milk) was consumed predominantly as whole milk (12\% consumers $v$. $2 \%$ consumers of reduced-fat or non-fat milk).

\section{Per capita intake of dairy products}

Among all Brazilians, per capita intake of total dairy products was 142 (SE 2.1) g/d, or approximately one portion per day as milk accounted for the majority of total dairy intake (Table 1). Compared with residents in rural areas of Brazil, urban residents consumed a greater number of milk, cheese, yoghurt and total dairy product portions per day $(P<0 \cdot 001)$. Among all Brazilians, adolescents and the elderly consumed more milk and total dairy products (g/d and portions/d) than adults aged 19-59 years $(P<0 \cdot 001$; Table 2). Cheese consumption (portions/d) was comparable between adults and the elderly, although higher than intake by adolescents $(P<0 \cdot 001)$. Yoghurt provided $0 \cdot 1$ dairy portions/d for Brazilians.

\section{Nutrients from dairy products}

On a per capita basis, dairy products accounted for $6 \cdot 1 \%$ of total energy intake in the population aged $\geq 10$ years and a generally comparable percentage of protein, carbohydrate, added sugars and cholesterol (Table 3). Dairy products accounted for slightly over one-third of daily intakes of dietary $\mathrm{Ca}(37.9 \%)$ and vitamin D (35.9\%), and $10 \cdot 2-18.7 \%$ of riboflavin, $\mathrm{P}$, vitamin $\mathrm{B}_{12}$, vitamin $\mathrm{A}$ and $\mathrm{K}$. In the population aged $\geq 10$ years, dairy products also accounted for $16.9 \%$ of saturated fat, $11.1 \%$ of total sugars and $4.3 \%$ of added sugars.
Although percentage nutrient contributions across location of household (i.e. urban $v$. rural) or age were not compared statistically, dairy products appeared to account for a lower percentage of total dietary nutrient intakes by individuals living in rural areas compared with urban areas, which is consistent with the lower overall dairy product intake by rural residents (Table 3). Percentage contributions of dairy products to nutrient intakes by age group are shown in Table 4. Compared with adolescents and adults, dairy products appeared to account for a higher percentage of total nutrient intakes in the elderly.

\section{Discussion}

Results of the present study provide nationally representative estimates of dairy product consumption in Brazil and contributions of dairy products to intakes of macronutrients and key micronutrients based on dietary records collected from 34003 individuals aged $\geq 10$ years in the first Individual Food Intake component of the Brazilian Household Budget Survey (2008-2009).

The 2006 Brazilian dietary guidelines recommend daily intake of three portions of milk and dairy products ${ }^{(12,13)}$. Mean intake of total dairy products was estimated at 0.9 portions/d among Brazilians aged $\geq 10$ years, and from $0 \cdot 7$ to 1.1 portions/d among sub-populations defined by location of household or age. Results from this assessment show that per capita intake of dairy products is well below the 2006 recommended intake for all Brazilians, regardless of household location or age.

Findings from the current analysis of nationally representative data are consistent with studies showing that dairy intake by adolescents and adults within selected areas in Brazil do not meet recommended levels as quantified in the 2006 guidance $^{(18-22)}$. For example, in a recent study of adults 18-60 years of age in Northeastern Brazil, the average intake of dairy products was 1.14

Table 2 Percentage of consumers and per capita intake of dairy products in the Brazilian population aged $\geq 10$ years by age group. Individual Food Intake 2008-2009; first day of intake

\begin{tabular}{|c|c|c|c|c|c|c|c|c|c|c|c|c|c|}
\hline & \multirow{2}{*}{\multicolumn{3}{|c|}{$\begin{array}{c}\text { Adolescents 10-18 years } \\
(n \text { 6939) (1) }\end{array}$}} & \multirow{2}{*}{\multicolumn{3}{|c|}{$\begin{array}{l}\text { Adults 19-59 years } \\
\quad(n 22742)(2)\end{array}$}} & \multirow{2}{*}{\multicolumn{3}{|c|}{$\begin{array}{l}\text { Elderly } \geq 60 \text { years } \\
\quad(n 4322)(3)\end{array}$}} & \multicolumn{4}{|c|}{$P$ value } \\
\hline & & & & & & & & & & \multirow{2}{*}{$\frac{\text { Overall }}{1 \text { v. } 2 \text { v. } 3}$} & \multicolumn{3}{|c|}{ Pairwise } \\
\hline & $\%$ & Mean & SE & $\%$ & Mean & SE & $\%$ & Mean & SE & & 1 v. 2 & 1 v. 3 & 2 v. 3 \\
\hline Total dairy* $(\mathrm{g} / \mathrm{d})$ & 64 & 162 & $4 \cdot 3$ & 60 & 131 & 2.4 & 69 & 165 & 5.5 & $<0.001$ & $<0.001$ & 0.977 & $<0.001$ \\
\hline Milk† (g/d) & 59 & 145 & 4.2 & 54 & 113 & $2 \cdot 1$ & 62 & 148 & $5 \cdot 2$ & $<0.001$ & $<0.001$ & 0.951 & $<0.001$ \\
\hline Cheese $(\mathrm{g} / \mathrm{d})$ & 9 & 4 & 0.3 & 15 & 7 & 0.4 & 18 & 9 & 0.7 & $<0.001$ & $<0.001$ & $<0.001$ & 0.030 \\
\hline Yoghurt (g/d) & 5 & 14 & 1.3 & 4 & 10 & 0.8 & 4 & 8 & 1.0 & $<0.001$ & 0.063 & $<0.001$ & 0.043 \\
\hline Total dairy,$\ddagger$ (portions/d) & 64 & 1.0 & 0.03 & 60 & 0.9 & 0.02 & 69 & 1.1 & 0.04 & $<0.05$ & $<0.001$ & 0.084 & $<0.001$ \\
\hline Milk†,‡ (portions/d) & 59 & 0.8 & 0.02 & 54 & 0.6 & 0.01 & 62 & 0.8 & 0.03 & $<0.05$ & $<0.001$ & 0.963 & $<0.001$ \\
\hline Cheesef (portions/d) & 9 & 0.1 & 0.01 & 15 & 0.2 & 0.01 & 18 & 0.2 & 0.02 & $<0.05$ & $<0.001$ & $<0.001$ & 0.088 \\
\hline Yoghurtł (portions/d) & 5 & 0.1 & 0.01 & 4 & 0.1 & $<0.05$ & 4 & 0.1 & 0.01 & $<0.05$ & 0.105 & 0.003 & 0.129 \\
\hline
\end{tabular}

*Total dairy values may not equal sum of milk, cheese and yoghurt values due to rounding.

†Milk includes plain and flavoured milk, milk drinks, grains cooked in milk and milk in coffee.

¥Weight per portion: milk, $182 \mathrm{~g}$; milk-based smoothies, $171 \mathrm{~g}$; grains cooked in milk, $195 \mathrm{~g}$; powdered milk, 26 or $34.5 \mathrm{~g}$; cheese, 30 to $50 \mathrm{~g}, 100 \mathrm{~g}$ for ricotta cheese; yoghurt, $165 \mathrm{~g}$. 
Table 3 Percentage contributions of dairy products to total nutrient intakes in the Brazilian population aged $\geq 10$ years, overall and by household location. Individual Food Intake 2008-2009; first day of intake

\begin{tabular}{|c|c|c|c|c|c|c|c|c|c|c|c|c|c|c|c|}
\hline \multirow[b]{3}{*}{ Nutrient } & \multicolumn{5}{|c|}{ Brazil (n 34 003) } & \multicolumn{5}{|c|}{ Urban (n 25753 ) } & \multicolumn{5}{|c|}{ Rural ( $n$ 8250) } \\
\hline & \multirow[b]{2}{*}{$\begin{array}{c}\text { Total } \\
\text { intake }\end{array}$} & \multicolumn{4}{|c|}{$\%$ from } & \multirow[b]{2}{*}{$\begin{array}{c}\text { Total } \\
\text { intake }\end{array}$} & \multicolumn{4}{|c|}{$\%$ from } & \multirow[b]{2}{*}{$\begin{array}{c}\text { Total } \\
\text { intake }\end{array}$} & \multicolumn{4}{|c|}{$\%$ from } \\
\hline & & $\begin{array}{l}\text { Total } \\
\text { dairy* }\end{array}$ & Milk & Cheese & Yoghurt & & $\begin{array}{c}\text { Total } \\
\text { dairy }\end{array}$ & Milk & Cheese & Yoghurt & & $\begin{array}{l}\text { Total } \\
\text { dairy* }\end{array}$ & Milk & Cheese & Yoghurt \\
\hline Energy (kJ) & 8033 & $6 \cdot 1$ & 4.5 & $1 \cdot 1$ & 0.5 & 8017 & $6 \cdot 4$ & 4.6 & $1 \cdot 2$ & 0.6 & 8100 & 4.6 & 3.7 & 0.7 & 0.2 \\
\hline Energy (kcal) & 1920 & $6 \cdot 1$ & 4.5 & $1 \cdot 1$ & 0.5 & 1916 & $6 \cdot 4$ & $4 \cdot 6$ & $1 \cdot 2$ & 0.6 & 1936 & 4.6 & 3.7 & 0.7 & 0.2 \\
\hline Protein $(\mathrm{g})$ & $80 \cdot 2$ & $7 \cdot 3$ & $5 \cdot 0$ & 1.8 & 0.5 & $79 \cdot 1$ & $7 \cdot 7$ & $5 \cdot 3$ & 1.9 & 0.5 & $86 \cdot 0$ & $5 \cdot 3$ & $4 \cdot 1$ & 1.0 & 0.2 \\
\hline Carbohydrate $(\mathrm{g})$ & 266 & 4.0 & 3.3 & 0.1 & 0.6 & 265 & 4.3 & 3.5 & 0.1 & 0.6 & 273 & $2 \cdot 8$ & 2.5 & 0.1 & 0.2 \\
\hline Total sugars $(\mathrm{g})$ & 94.2 & $11 \cdot 1$ & $9 \cdot 3$ & 0.3 & 1.4 & $96 \cdot 3$ & 11.4 & 9.5 & 0.4 & 1.6 & 83.3 & $9 \cdot 1$ & $8 \cdot 3$ & 0.2 & 0.6 \\
\hline Added sugars $(\mathrm{g})$ & 64.9 & $4 \cdot 3$ & 3.2 & 0.0 & 1.1 & $66 \cdot 4$ & 4.6 & 3.4 & 0.0 & 1.2 & $57 \cdot 6$ & $2 \cdot 4$ & 2.0 & 0.0 & 0.4 \\
\hline Total fat $(\mathrm{g})$ & 58.5 & $10 \cdot 0$ & $6 \cdot 8$ & $2 \cdot 6$ & 0.6 & $59 \cdot 2$ & $10 \cdot 3$ & $6 \cdot 8$ & $2 \cdot 8$ & 0.7 & 54.9 & 8.4 & $6 \cdot 3$ & $1 \cdot 8$ & 0.3 \\
\hline Saturated fat (g) & $20 \cdot 3$ & $16 \cdot 9$ & $11 \cdot 1$ & 4.8 & 1.0 & 20.7 & $17 \cdot 2$ & $11 \cdot 1$ & $5 \cdot 0$ & $1 \cdot 1$ & $18 \cdot 0$ & 14.9 & 11.0 & 3.4 & 0.5 \\
\hline Cholesterol (mg) & 248 & $7 \cdot 4$ & 4.9 & $2 \cdot 0$ & 0.4 & 242 & 7.9 & $5 \cdot 2$ & $2 \cdot 2$ & 0.5 & 275 & $5 \cdot 2$ & 3.8 & $1 \cdot 1$ & 0.2 \\
\hline Vitamin A ( $\mu \mathrm{g}$ RAE) & 500 & $11 \cdot 1$ & 7.4 & $3 \cdot 1$ & 0.6 & 515 & $11 \cdot 3$ & $7 \cdot 4$ & 3.3 & 0.7 & 425 & $9 \cdot 8$ & $7 \cdot 3$ & $2 \cdot 2$ & $0 . \overline{3}$ \\
\hline Riboflavin (mg) & 1.62 & $18 \cdot 7$ & $15 \cdot 9$ & 1.6 & 1.3 & 1.65 & $19 \cdot 0$ & $16 \cdot 0$ & 1.7 & 1.4 & 1.48 & $16 \cdot 9$ & $15 \cdot 2$ & 1.1 & 0.6 \\
\hline Vitamin $B_{6}(\mathrm{mg})$ & 1.49 & 4.3 & 3.7 & 0.3 & 0.3 & 1.52 & 4.4 & 3.8 & 0.4 & 0.3 & 1.36 & 3.8 & 3.4 & 0.2 & 0.1 \\
\hline Vitamin $B_{12}(\mu \mathrm{g})$ & 5.08 & $12 \cdot 6$ & $10 \cdot 3$ & 1.4 & 1.0 & 5.04 & $13 \cdot 2$ & $10 \cdot 6$ & 1.5 & $1 \cdot 1$ & $5 \cdot 31$ & $9 \cdot 8$ & 8.6 & 0.8 & 0.4 \\
\hline Vitamin $D(\mu \mathrm{g})$ & 3.22 & 35.9 & $35 \cdot 3$ & 0.4 & 0.2 & 3.00 & $40 \cdot 9$ & $40 \cdot 2$ & 0.5 & 0.2 & 4.34 & 18.5 & $18 \cdot 3$ & 0.2 & 0.1 \\
\hline $\mathrm{Ca}(\mathrm{mg})$ & 516 & 37.9 & $27 \cdot 6$ & 7.7 & $2 \cdot \overline{6}$ & 522 & 38.9 & 28.0 & 8.1 & $2 \cdot 8$ & 483 & 32.0 & $25 \cdot 5$ & $5 \cdot \overline{3}$ & $1 \cdot 2$ \\
\hline$P(\mathrm{mg})$ & 976 & $17 \cdot 0$ & $12 \cdot 1$ & 3.8 & 1.1 & 970 & $17 \cdot 9$ & $12 \cdot 5$ & $4 \cdot 1$ & $1 \cdot 2$ & 1011 & $12 \cdot 7$ & $10 \cdot 0$ & $2 \cdot 3$ & 0.4 \\
\hline $\mathrm{Mg}(\mathrm{mg})$ & 243 & 7.6 & $6 \cdot 3$ & 0.7 & 0.5 & 239 & 8.0 & 6.6 & 0.8 & 0.6 & 267 & 5.5 & 4.8 & 0.4 & 0.2 \\
\hline $\mathrm{Zn}(\mathrm{mg})$ & 11.3 & $6 \cdot 6$ & 4.6 & 1.5 & 0.5 & 11.2 & 6.9 & 4.8 & 1.6 & 0.5 & 11.5 & $5 \cdot 1$ & 3.9 & 1.0 & 0.2 \\
\hline $\mathrm{Na}(\mathrm{mg})$ & 3190 & 4.4 & $2 \cdot 3$ & 1.9 & 0.2 & 3178 & 4.6 & $2 \cdot 3$ & $2 \cdot 1$ & 0.2 & 3248 & 3.4 & $2 \cdot 1$ & $1 \cdot 2$ & 0.1 \\
\hline $\mathrm{K}(\mathrm{mg})$ & 2390 & $10 \cdot 2$ & 9.0 & 0.5 & $0 . \overline{7}$ & 2365 & $10 \cdot 8$ & $9 \cdot 4$ & 0.5 & 0.8 & 2517 & 7.8 & $7 \cdot 3$ & $0 . \overline{3}$ & 0.3 \\
\hline
\end{tabular}

$R A E$, retinol activity equivalents.

*Total dairy products include milk (plain and flavoured milk, milk drinks, grains cooked in milk and milk in coffee), cheese and yoghurt.

servings/d, with the majority of servings consumed as whole milk ${ }^{(22)}$. Based on an assessment of diet quality among adults in São Paulo, intake of milk and dairy products was estimated at approximately 0.7 portions $/ \mathrm{d}^{(9)}$.

Dietary guidance for Americans aged $\geq 9$ years recommends consumption of three cup-equivalents of fat-free or low-fat milk and milk products daily ${ }^{(23)}$. Mean consumption of dairy products by adult men and women aged $\geq 20$ years based on data collected in 2009-2010 was 1.95 and 1.50 cup-equivalents, respectively, with fluid milk accounting for half of total dairy intake and cheese largely accounting for the balance ${ }^{(24)}$. Results from the current analysis suggest that the gap between reported and recommended intake of dairy servings may be larger for Brazilians than Americans. Lack of knowledge about the milk food group recommendations and portion sizes of milk products has been identified as a core barrier for consumer adherence to dietary guidance for this food group in the USA ${ }^{(25)}$. Efforts to educate the Brazilian population about dairy recommendations, including qualitative information about minimally $v$. more processed dairy products and quantitative information on dairy product portions, could provide a useful strategy to improve diet quality through increased consumption of nutrient-dense dairy products.

The relatively high overall contributions of dairy products to nutrient intakes among Brazilians indicate that dairy products are an important source of several nutrients in the diet, including nutrients with a high prevalence of inadequate or suboptimal intakes, namely $\mathrm{Ca}$, vitamin $\mathrm{A}$, vitamin $\mathrm{D}, \mathrm{Mg}, \mathrm{P}$ and $\mathrm{K}^{(2-5)}$. These findings are consistent with analyses of diets in other countries in North America and Europe showing that dairy products are a substantial source of $\mathrm{Ca}$ and other nutrients such as $\mathrm{K}, \mathrm{Mg}$ and $\mathrm{P}^{(26-29)}$. Analyses of nutrient intakes based on dietary pattern modelling in the USA have shown that daily consumption of multiple portions of dairy products is important for meeting recommended intakes of $\mathrm{Ca}$ along with other nutrients in the $\operatorname{diet}^{(30,31)}$.

Across all age groups, and in particular elderly adults, dairy products accounted for a large proportion of total saturated fat intake. The dietary guidelines in Brazil encourage low-fat products for adults to minimize consumption of saturated fat ${ }^{(11,12)}$. Although the evidence has been inconsistent, some meta-analyses have not found adverse effects of high-fat dairy intake on cardiovascular risk $^{(32,33)}$. In a recent longitudinal study of adults in Brazil, total dairy intake (the majority of which was full-fat) was inversely associated with measures of glycaemia and insulinaemia ${ }^{(34)}$, results potentially attributed to SFA in the dairy products. Nutrition education efforts could help guide consumers to lower-fat dairy products such as milk and yoghurt in place of cheese while further research clarifies the specific role of dairy fats in health.

Dairy products accounted for approximately $4 \%$ of added sugars in the diets of adults and the elderly, and approximately $6 \%$ in the diets of adolescents. Consistent with the current study, previous research has indicated 
Table 4 Percentage contributions of dairy products to total nutrient intakes in the Brazilian population aged $\geq 10$ years by age group. Individual Food Intake 2008-2009; first day of intake

\begin{tabular}{|c|c|c|c|c|c|c|c|c|c|c|c|c|c|c|c|}
\hline \multirow[b]{3}{*}{ Nutrient } & \multicolumn{5}{|c|}{ Adolescents $10-18$ years ( $n$ 6939) } & \multicolumn{5}{|c|}{ Adults $19-59$ years ( $n$ 22 742) } & \multicolumn{5}{|c|}{ Elderly $\geq 60$ years $(n$ 4322) } \\
\hline & \multirow[b]{2}{*}{$\begin{array}{c}\text { Total } \\
\text { intake }\end{array}$} & \multicolumn{4}{|c|}{$\%$ from } & \multirow[b]{2}{*}{$\begin{array}{c}\text { Total } \\
\text { intake }\end{array}$} & \multicolumn{4}{|c|}{$\%$ from } & \multirow[b]{2}{*}{$\begin{array}{c}\text { Total } \\
\text { intake }\end{array}$} & \multicolumn{4}{|c|}{$\%$ from } \\
\hline & & $\begin{array}{l}\text { Total } \\
\text { dairy* }\end{array}$ & Milk & Cheese & Yoghurt & & $\begin{array}{l}\text { Total } \\
\text { dairy* }\end{array}$ & Milk & Cheese & Yoghurt & & $\begin{array}{l}\text { Total } \\
\text { dairy* }\end{array}$ & Milk & Cheese & Yoghurt \\
\hline Energy (kJ) & 8569 & $6 \cdot 4$ & $5 \cdot 1$ & $0 \cdot 6$ & 0.7 & 8109 & $5 \cdot 7$ & $4 \cdot 0$ & $1 \cdot 1$ & 0.5 & 6853 & $8 \cdot 1$ & $6 \cdot 0$ & $1 \cdot 7$ & $0 \cdot 4$ \\
\hline Energy (kcal) & 2048 & $6 \cdot 4$ & $5 \cdot 1$ & 0.6 & 0.7 & 1938 & $5 \cdot 7$ & $4 \cdot 0$ & $1 \cdot 1$ & 0.5 & 1638 & $8 \cdot 1$ & $6 \cdot 0$ & $1 \cdot 7$ & 0.4 \\
\hline Protein (g) & $79 \cdot 9$ & $7 \cdot 4$ & $5 \cdot 8$ & $1 \cdot 0$ & $0 \cdot 6$ & $82 \cdot 2$ & $6 \cdot 8$ & $4 \cdot 5$ & 1.9 & 0.5 & $71 \cdot 2$ & $9 \cdot 8$ & $6 \cdot 8$ & $2 \cdot 7$ & 0.4 \\
\hline Carbohydrate (g) & 290 & $4 \cdot 7$ & $4 \cdot 0$ & 0.0 & 0.7 & 267 & $3 \cdot 6$ & $2 \cdot 9$ & $0 \cdot 1$ & 0.6 & 228 & $5 \cdot 0$ & $4 \cdot 3$ & 0.2 & 0.4 \\
\hline Total sugars $(\mathrm{g})$ & $109 \cdot 5$ & $12 \cdot 1$ & $10 \cdot 4$ & 0.1 & $1 \cdot 6$ & $93 \cdot 3$ & $10 \cdot 2$ & $8 \cdot 4$ & 0.4 & $1 \cdot 4$ & $76 \cdot 4$ & $14 \cdot 3$ & $12 \cdot 6$ & 0.7 & $1 \cdot 1$ \\
\hline Added sugars $(\mathrm{g})$ & $79 \cdot 4$ & $5 \cdot 7$ & 4.5 & $0 \cdot 0$ & $1 \cdot 2$ & $64 \cdot 4$ & $3 \cdot 8$ & $2 \cdot 7$ & 0.0 & $1 \cdot 1$ & $46 \cdot 3$ & $4 \cdot 3$ & $3 \cdot 4$ & 0.0 & 0.9 \\
\hline Total fat $(\mathrm{g})$ & $63 \cdot 6$ & $9 \cdot 5$ & $7 \cdot 4$ & $1 \cdot 4$ & 0.8 & $59 \cdot 0$ & $9 \cdot 5$ & $6 \cdot 1$ & $2 \cdot 8$ & 0.6 & $48 \cdot 9$ & $13 \cdot 9$ & $9 \cdot 3$ & $4 \cdot 1$ & 0.5 \\
\hline Saturated fat $(\mathrm{g})$ & $22 \cdot 3$ & $15 \cdot 9$ & $12 \cdot 1$ & $2 \cdot 6$ & $1 \cdot 2$ & $20 \cdot 4$ & $16 \cdot 1$ & $10 \cdot 1$ & $5 \cdot 0$ & 0.9 & $17 \cdot 1$ & $23 \cdot 1$ & $14 \cdot 9$ & $7 \cdot 4$ & $0 \cdot 8$ \\
\hline Cholesterol (mg) & 255 & $7 \cdot 5$ & $5 \cdot 8$ & $1 \cdot 1$ & $0 . \overline{6}$ & 253 & $7 \cdot 0$ & $4 \cdot 4$ & $2 \cdot 1$ & 0.4 & 212 & $9 \cdot 9$ & $6 \cdot 4$ & $3 \cdot 1$ & 0.4 \\
\hline Vitamin A ( $\mu \mathrm{g}$ RAE) & 469 & $11 \cdot 4$ & $8 \cdot 8$ & $1 \cdot 8$ & 0.9 & 508 & $10 \cdot 5$ & $6 \cdot 6$ & $3 \cdot 3$ & 0.6 & 507 & $13 \cdot 8$ & $9 \cdot 1$ & $4 \cdot 3$ & 0.4 \\
\hline Riboflavin (mg) & $1 \cdot 69$ & $19 \cdot 1$ & $16 \cdot 7$ & $0 \cdot 8$ & $1 \cdot 6$ & $1 \cdot 62$ & $17 \cdot 6$ & $14 \cdot 7$ & $1 \cdot 7$ & $1 \cdot 2$ & 1.50 & $24 \cdot 5$ & $21 \cdot 1$ & $2 \cdot 4$ & 0.9 \\
\hline Vitamin $B_{6}(\mathrm{mg})$ & $1 \cdot 49$ & 4.9 & $4 \cdot 4$ & 0.2 & 0.4 & 1.52 & $4 \cdot 0$ & $3 \cdot 3$ & 0.4 & 0.3 & $1 \cdot 36$ & $5 \cdot 5$ & $4 \cdot 8$ & 0.5 & 0.2 \\
\hline Vitamin $B_{12}(\mu \mathrm{g})$ & 4.96 & $13 \cdot 7$ & $11 \cdot 7$ & $0 \cdot 8$ & $1 \cdot 3$ & $5 \cdot 20$ & $11 \cdot 6$ & $9 \cdot 3$ & $1 \cdot 4$ & 0.9 & $4 \cdot 64$ & $16 \cdot 6$ & $13 \cdot 8$ & $2 \cdot 0$ & 0.7 \\
\hline Vitamin $D(\mu \mathrm{g})$ & 3.45 & $38 \cdot 8$ & $38 \cdot 4$ & 0.2 & 0.2 & $3 \cdot 18$ & $33 \cdot 7$ & $33 \cdot 1$ & 0.5 & 0.2 & $3 \cdot 12$ & $42 \cdot 4$ & $41 \cdot 7$ & 0.6 & $0 \cdot 1$ \\
\hline $\mathrm{Ca}(\mathrm{mg})$ & 538 & $37 \cdot 7$ & $30 \cdot 4$ & $4 \cdot 1$ & $3 \cdot 1$ & 511 & $36 \cdot 2$ & $25 \cdot 5$ & $8 \cdot 2$ & $2 \cdot 5$ & 507 & $46 \cdot 5$ & $34 \cdot 2$ & $10 \cdot 4$ & 1.9 \\
\hline$P(m g)$ & 991 & $17 \cdot 1$ & $13 \cdot 9$ & $1 \cdot 8$ & $1 \cdot 4$ & 988 & $15 \cdot 9$ & $10 \cdot 9$ & $4 \cdot 0$ & $1 \cdot 1$ & 899 & $22 \cdot 6$ & $15 \cdot 7$ & $6 \cdot 1$ & 0.8 \\
\hline $\mathrm{Mg}(\mathrm{mg})$ & 246 & $8 \cdot 3$ & $7 \cdot 3$ & $0 \cdot 4$ & 0.7 & 246 & $7 \cdot 0$ & $5 \cdot 7$ & 0.8 & 0.5 & 226 & $9 \cdot 6$ & $8 \cdot 1$ & $1 \cdot 1$ & 0.4 \\
\hline $\mathrm{Zn}(\mathrm{mg})$ & $11 \cdot 2$ & $6 \cdot 8$ & $5 \cdot 4$ & 0.9 & $0 \cdot 6$ & $11 \cdot 6$ & $6 \cdot 1$ & $4 \cdot 1$ & $1 \cdot 6$ & $0 \cdot 4$ & $9 \cdot 9$ & $9 \cdot 1$ & $6 \cdot 4$ & $2 \cdot 3$ & 0.4 \\
\hline $\mathrm{Na}(\mathrm{mg})$ & 3224 & $3 \cdot 7$ & $2 \cdot 7$ & 0.9 & 0.2 & 3237 & $4 \cdot 0$ & $1 \cdot 9$ & $2 \cdot 0$ & $0 \cdot 1$ & 2904 & $7 \cdot 2$ & $3 \cdot 7$ & $3 \cdot 3$ & $0 \cdot 1$ \\
\hline $\mathrm{K}(\mathrm{mg})$ & 2369 & $11 \cdot 6$ & $10 \cdot 4$ & 0.2 & 0.9 & 2418 & $9 \cdot 4$ & $8 \cdot 2$ & 0.5 & $0 \cdot 7$ & 2280 & $12 \cdot \overline{6}$ & $11 \cdot 2$ & $0 \cdot 8$ & 0.5 \\
\hline
\end{tabular}

RAE, retinol activity equivalents.

*Total dairy products include milk (plain and flavoured milk, milk drinks, grains cooked in milk and milk in coffee), cheese and yoghurt.

that sweetened and full-fat dairy products such as flavoured milks are a contributor to intake of added sugars and solid fats, particularly among adolescents ${ }^{(35)}$. These processed dairy products are among the foods for which limited consumption is recommended in the 2014 Brazilian dietary guidelines. Nutrition education efforts targeted to adolescents could help this population increase dairy consumption while minimizing intake of added sugars, thus improving the overall nutritional quality of their diets.

Apparent differences in the percentage contributions of dairy products to nutrient intakes by household location and age group observed in the current analysis may largely be attributed to differences in dairy product consumption across sub-populations. The proportion of dietary vitamin $\mathrm{D}$ intake provided by dairy products for residents in rural areas was considerably lower than the proportion provided for urban residents (18.5\% v. $40.9 \%$, respectively). The lower contribution may be a result of several factors, including a greater proportion of residents in rural areas consuming fresh cow's milk which was not assumed to contain vitamin $\mathrm{D}$ in the food composition database used to process nutrient intakes in the Brazilian survey ${ }^{(14)}$. The potentially increased contributions of dairy products to nutrient intakes among the elderly may be attributed to their greater per capita intake of dairy products and overall lower energy intake and nutrient intakes. The exception to higher contributions of dairy products to nutrient intakes by the elderly was added sugars, presumably because of relatively low intake of flavoured milk and milk drinks in this sub-population.

Bezerra and colleagues recently compared food intakes by Brazilian adults with American adults and found that the percentage of American adults consuming milk was $47 \%$ compared with $23 \%$ among Brazilians, while $62 \%$ of adults in the US consumed dairy products (other than milk) compared with $18 \%$ in Brazil ${ }^{(36)}$. The percentage of total energy intake accounted for by milk and dairy products combined in the USA was $9.6 \% v .4 .5 \%$ in Brazil ${ }^{(36)}$. The higher energy contributions from total dairy products in the current analysis for adults (5.7\%) and elderly adults $(8.1 \%)$ in Brazil, and the higher percentage of adults reporting intake of milk, may in part reflect our inclusion of milk consumed as part of coffee drinks in the estimates of total milk intake. Milk in coffee was the only source of dairy product intake for $25 \%$ of the population of adults and elderly adults in Brazil. Given the frequency of coffee with milk consumption by adults in Brazil, this source of milk is an important component of total dairy consumption among Brazilians. In the USA, $8 \%$ of fluid milk reported consumed by adults was plain milk added to another beverage ${ }^{(37)}$.

Strengths of the present analysis include use of a recent and large nationally representative sample to estimate nutrient intakes. Estimates of intake for sub-populations categorized by location of household and age group allow for identification of dietary patterns unique to these individuals. It is also 
important to consider limits of the cross-sectional data analysis. As with all estimates based on dietary records, these estimates are limited by the accuracy of the information provided in the records and the accuracy to which the assigned nutrient composition data reflect the nutrient composition of the foods consumed. IBGE evaluated energy intakes collected in the dietary records and concluded that results were consistent with data collected in similar studies $^{(14)}$. Nutrient composition data for selected nutrients, including vitamin $\mathrm{D}$, were assigned based on composition data from the USA. Most milk in the USA is voluntarily fortified with vitamin D at a level of $400 \mathrm{IU}$ per quart, which is equivalent to approximately $2.5 \mu \mathrm{g}$ vitamin D per $240 \mathrm{ml}$ serving. Milk in Brazil may contain added vitamin D, although standard milk is typically not fortified. The estimated intakes of dietary vitamin $\mathrm{D}$ in the current analysis therefore may not necessarily reflect current consumption patterns. Additionally, levels of sugars added to beverages were based on standardized calculations rather than recorded amounts.

In the present analysis dairy product intake (grams and portions) and nutrient contributions from dairy products were estimated from reported intakes of milk, cheese and yoghurt. With the exception of milk consumed in coffee, mixtures were not disaggregated to identify dairy product components, therefore our findings may slightly underestimate total dairy product intake. Additionally, all estimates are based on one day of food records and may not be representative of usual intakes, although estimates based on one day are appropriate to estimate mean intakes by a population $^{(16,17)}$.

\section{Conclusions}

Results from the present study indicate that dairy product consumption is well below the 2006 recommended levels of intake for most of the population aged $\geq 10$ years in Brazil, regardless of location of residence or age. Dairy products were significant contributors to dietary intake (11.1-37.9\% of daily intake) of several nutrients including $\mathrm{Ca}, \mathrm{P}$ and vitamin $\mathrm{A}$, all of which are nutrients of concern in Brazil. Dairy products also contributed to intakes of saturated fat (16.9\%), total sugars $(11.1 \%)$ and added sugars ( $4.3 \%)$. Education efforts to raise awareness about current guidelines for dairy intake may serve to improve diet quality of individuals in Brazil.

\section{Acknowledgements}

Acknowledgements: The authors thank Juliana Peccin, PepsiCo Brazil, for her guidance on dietary guidelines in Brazil and review of the manuscript. Financial support: This work was supported by PepsiCo Global R\&D Nutrition Sciences. The opinions in this study are those of the authors and do not necessarily represent the opinions or policies of
PepsiCo, Inc. Conflict of interest: This data analysis was fully funded by PepsiCo, Inc. Authorship: M.M.M. and L.M.B. designed the study, completed the analyses and interpreted the data. M.M.M. wrote the manuscript. L.D.T., L.S.H. and D.R.B. were responsible for the study conception. All authors read, critically reviewed and approved the final manuscript. Ethics of buman subject participation: The Brazilian Household Budget survey was conducted in accordance with Federal Law number 5534 which guarantees confidentiality of the gathered information.

\section{References}

1. Miller GD, Jarivs JK \& McBean LD (2007) Handbook of Dairy Foods and Nutrition, 3rd ed. Boca Raton, FL: CRC Press.

2. Araujo MC, Bezerra IN, Barbosa FdS et al. (2013) Macronutrient consumption and inadequate micronutrient intake in adults. Rev Saude Publica 47, Suppl. 1, 177S-189S.

3. Fisberg RM, Marchioni DM, Castro MA et al. (2013) Inadequate nutrient intake among the Brazilian elderly: National Dietary Survey 2008-2009. Rev Saude Publica 47, Suppl. 1, 222S-230S.

4. Veiga GV, Costa RS, Araujo MC et al. (2013) Inadequate nutrient intake in Brazilian adolescents. Rev Saude Publica 47, Suppl. 1, 212S-221S.

5. Instituto Brasileiro de Geografia e Estatística (2011) Pesquisa de Orçamentos Familiares 2008-2009: Análise do Consumo Alimentar Pessoal no Brasil. Rio de Janeiro: IBGE.

6. Moore LL, Singer MR, Qureshi MM et al. (2012) Food group intake and micronutrient adequacy in adolescent girls. Nutrients 4, 1692-1708.

7. McGill CR, Fulgoni VL 3rd, DiRienzo D et al. (2008) Contribution of dairy products to dietary potassium intake in the United States population. J Am Coll Nutr 27, 44-50.

8. Weinberg LG, Berner LA \& Groves JE (2004) Nutrient contributions of dairy foods in the United States, Continuing Survey of Food Intakes by Individuals, 1994-1996, 1998. J Am Diet Assoc 104, 895-902.

9. Fisberg RM, Morimoto JM, Slater B et al. (2006) Dietary quality and associated factors among adults living in the state of Sao Paulo, Brazil. J Am Diet Assoc 106, 2067-2072.

10. Krebs-Smith SM, Guenther PM, Subar AF et al. (2010) Americans do not meet federal dietary recommendations. J Nutr 140, 1832-1838.

11. Ministry of Health of Brazil, Secretariat of Health Care, Primary Health Care Department (2014) Dietary Guidelines for the Brazilian Population/Ministry of Health of Brazil, Secretariat of Health Care, Primary Health Care Department; translated by Carlos Augusto Monteiro. Brasília: Ministry of Health of Brazil.

12. Coordenação Geral da Política de Alimentação e Nutrição, Secretaria de Atenção à Saúde, Ministério da Saúde (2006) Guia Alimentar para a População Brasileira: Promovendo a Alimentação Saudável. Brasília: Ministério da Saúde.

13. Sichieri R, Chiuve SE, Pereira RA et al. (2010) Dietary recommendations: comparing dietary guidelines from Brazil and the United States. Cad Saude Publica 26, 2050-2058.

14. Instituto Brasileiro de Geografia e Estatística (2011) Pesquisa de Orçamentos Familiares 2008-2009: Tabelas de Composição Nutricional dos Alimentos Consumidos no Brasil. Rio de Janeiro: IBGE.

15. Krebs-Smith SM, Kott PS \& Guenther PM (1989) Mean proportion and population proportion: two answers to the same question? J Am Diet Assoc 89, 671-676. 
16. Willett W (1990) Nutritional Epidemiology. New York: Oxford University Press.

17. Dodd KW, Guenther PM, Freedman LS et al. (2006) Statistical methods for estimating usual intake of nutrients and foods: a review of the theory. J Am Diet Assoc 106, 1640-1650.

18. de Andrade SC, de Azevedo Barros MB, Carandina L et al. (2010) Dietary quality index and associated factors among adolescents of the state of Sao Paulo, Brazil. J Pediatr 156, 456-460.

19. Peters BS, Verly E Jr, Marchioni DM et al. (2012) The influence of breakfast and dairy products on dietary calcium and vitamin $\mathrm{D}$ intake in postpubertal adolescents and young adults. J Hum Nutr Diet 25, 69-74.

20. Molina MC, Bettiol H, Barbieri M et al. (2007) Food consumption by young adults living in Ribeirao Preto, SP, 2002/2004. Braz J Med Biol Res 40, 1257-1266.

21. Goncalves DF, Tinoco AL, Ribeiro Rde C et al. (2012) Nutritional status and epidemiological profile of elderly people. Arch Gerontol Geriatr 55, 1-4.

22. Pereira DD, Lima RP, de Lima RT et al. (2013) Association between obesity and calcium:phosphorus ratio in the habitual diets of adults in a city of Northeastern Brazil: an epidemiological study. Nutr J 12, 90.

23. US Department of Agriculture \& US Department of Health and Human Services (2010) Dietary Guidelines for Americans, 2010, 7th ed. Washington, DC: US Government Printing Office.

24. US Department of Agriculture, Agricultural Research Service (2013) Food Patterns Equivalents Intakes from Food: Mean Amounts Consumed per Individual, by Gender and Age, What We Eat in America, NHANES 2009-2010. Beltsville, MD: US Department of Agriculture, Agricultural Research Service.

25. Nicklas TA, Jahns L, Bogle ML et al. (2013) Barriers and facilitators for consumer adherence to the dietary guidelines for Americans: the HEALTH study. J Acad Nutr Diet 113, 1317-1331.

26. Welch AA, Fransen H, Jenab M et al. (2009) Variation in intakes of calcium, phosphorus, magnesium, iron and potassium in 10 countries in the European Prospective Investigation into Cancer and Nutrition study. Eur J Clin Nutr 63, Suppl. 4, S101-S121.

27. O'Neil CE, Keast DR, Fulgoni VL et al. (2012) Food sources of energy and nutrients among adults in the US: NHANES 2003-2006. Nutrients 4, 2097-2120.
28. Drewnowski A (2011) The contribution of milk and milk products to micronutrient density and affordability of the US diet. J Am Coll Nutr 30, 5 Suppl. 1, 422S-428S.

29. Coudray B (2011) The contribution of dairy products to micronutrient intakes in France. J Am Coll Nutr 30, 5 Suppl. 1, 410S-414S.

30. Gao X, Wilde PE, Lichtenstein AH et al. (2006) Meeting adequate intake for dietary calcium without dairy foods in adolescents aged 9 to 18 years (National Health and Nutrition Examination Survey 2001-2002). J Am Diet Assoc 106, $1759-1765$.

31. Fulgoni VL 3rd, Keast DR, Auestad N et al. (2011) Nutrients from dairy foods are difficult to replace in diets of Americans: food pattern modeling and an analyses of the National Health and Nutrition Examination Survey 20032006. Nutr Res 31, 759-765.

32. Soedamah-Muthu SS, Ding EL, Al-Delaimy WK et al. (2011) Milk and dairy consumption and incidence of cardiovascular diseases and all-cause mortality: dose-response metaanalysis of prospective cohort studies. Am J Clin Nutr $\mathbf{9 3}$, 158-171.

33. Benatar JR, Sidhu K \& Stewart RA (2013) Effects of high and low fat dairy food on cardio-metabolic risk factors: a meta-analysis of randomized studies. PLoS One $\mathbf{8}$, e76480.

34. Drehmer M, Pereira MA, Schmidt MI et al. (2015) Associations of dairy intake with glycemia and insulinemia, independent of obesity, in Brazilian adults: the Brazilian Longitudinal Study of Adult Health (ELSA-Brasil). Am J Clin Nutr 101, 775-782.

35. Pereira RA, Duffey KJ, Sichieri R et al. (2014) Sources of excessive saturated fat, trans fat and sugar consumption in Brazil: an analysis of the first Brazilian nationwide individual dietary survey. Public Health Nutr 17, 113-121.

36. Bezerra IN, Goldman J, Rhodes DG et al. (2014) Difference in adult food group intake by sex and age groups comparing Brazil and United States nationwide surveys. Nutr J 13, 74.

37. Sebastian RS, Goldman JD, Wilkinson Enns C et al. (2010) Fluid Milk Consumption in the United States: What We Eat in America, NHANES 2005-2006. Food Survey Research Group Dietary Data Brief no. 3. Beltsville, MD: US Department of Agriculture, Agricultural Research Service. 